\title{
Motivation, Gender, and Learner Performance of English as an L3 in the Xinjiang Uyghur Autonomous Region
}

\author{
Rayhangül Ahåt ${ }^{1,2}$ \\ ${ }^{1}$ College of Foreign Languages, Xinjiang University, Ürümqi, China \\ ${ }^{2}$ Course of Foreign Language Acquisition and Education, Kyoto University, Kyoto, Japan \\ Correspondence: Rayhangül Ahåt, Department of Second Language Acquisition, Kyoto University, Kyoto, Japan. \\ E-mail: rayhanahat@hotmail.com
}

\author{
Received: June 10, 2013 Accepted: July 4, 2013 Online Published: August 15, 2013 \\ doi:10.5539/elt.v6n9p158 URL: http://dx.doi.org/10.5539/elt.v6n9p158
}

\begin{abstract}
Gender is considered as one of the important variables that effects learner motivation in second or foreign language acquisition. It is also believed that learner motivation has an impact on learner performance as well. Using the expectancy-value theory model of achievement motivation, this study aimed at exploring (1) the impact of gender differences on motivation and (2) motivational variables that predict learner performance in the context of English as an L3. The participants in this study were ethnic minority students (mainly Uygur) of a university in the Xinjiang Uyghur Autonomous Region of China. Results of both quantitative and qualitative analyses showed that female students held greater attainment and intrinsic values than male students; the study results also revealed that expectancy and cost are motivational variables that better predict the minority students' EFL performance in the context of English as an L3. These findings support the notion that females are more interested in the target culture and interaction with its speakers than males in EFL learning. On the basis of these results, the author discusses possible factors that influence ethnic minority learners' motivation in learning English as an L3 and provides suggestions on how to motivate male students and help them to improve performance in the process of English teaching in the context of bilingual education in Xinjiang.
\end{abstract}

Keywords: learner motivation, learner performance, minority students, male and female learners, English as L3, expectancy-value theory

\section{Introduction}

\subsection{Learner Motivation}

The term motivation differs among the theorists and researchers from different fields and domains. In the expectancy-value theory model of achievement motivation, Eccles et al. (2004) defined learner motivation as the combination of individual's expectancy for success and their value beliefs in a task. They define expectancy as the individuals' beliefs about how well they will do on an upcoming task; it depends on learners' confidence in their intellectual abilities and on their estimation of the task difficulty, and relates to learners' sense of competence, self-efficacy and locus of control. In self-determination theory, competence refers to the feeling that one has the capacity to effectively carry out an action. Feelings of competence are promoted by communicating expectations that are challenging without being overwhelming. Deci, Ryan, and colleagues $(1985,1995,2000)$ include the need for competence as one of the three basic needs of human psychology and discussed how this need is a major reason for people to seek out optimal and challenging activities. Bandura $(1977,1986,1997)$ also mentioned the importance of expectancy in his self-efficacy theory. He defines self-efficacy as one's judgment of ability to complete a task successfully. It can affect efforts through expectations for success, and efficacy expectations determine how much effort learners will expend and how long they will persist at a given task. Learners' attributions of success or failure to internal or external factors such as effort, ability, and task difficulty also influence their motivation (Graham, 1988a; Eccles \& Wigfield, 2002; Tremblay \& Gardner, 1995) and the attributions learners make about their past experience has impact on their expectancy in pursuing or avoiding their goals (Weiner, 1985). Expectancy for success is incorporated in the above-mentioned motivational theories as an integral of part of the theory.

Regarding task values, Eccles et al. (2004) defines them as the qualities of different tasks and how those qualities 
influence individual's desire to do the task. They grouped the individual's value beliefs on a task into four types. Intrinsic value: the enjoyment or emotional incentives a person gets from doing the task and his/her subjective interest in the task; this is closely linked to intrinsic motivation in self-determination theory. Decy \& Ryan (1985, 2002) also define it as the enjoyment one feels while performing in an inherently interesting activity, as in the case of a learner who experiences a spontaneous sense of satisfaction in mastering linguistic and communicative challenges and elaborating on her capacities in the new language. Utility value: the individual's future goals for doing the task such as getting required credit at school, gaining a prestigious job in a society and so on. This component of the subjective task values is very similar to the external regulation of extrinsic motivation in self-determination theory in which the cause of an action is out of learners' own control. Attainment value: the personal importance of doing well on a given task. This refers to the needs and personal values that an activity fulfills and includes the following subcomponents: (a) conceptions of personality and capabilities, (b) long-range goals and plans, (c) ideal images of what one should like to be, and (d) schema regarding the proper roles of men and women (Eccles, 1994). Thus, in this sense, attainment value closely links to the more internalized form of external regulation in self-determination theory and ideal L2 self in the L2 motivational self system Cost: negative aspects of engaging in a task, such as performance anxiety, task difficulty, fear of failure, the time spent on doing a given task and so on. Choices are influenced by both negative and positive task characteristics and all choices are assumed to have costs associated with them (Wigfield el at. 2004), because learners will loose opportunities that result from making one choice rather than another. In this sense, task difficulty plays an important role in learners' choice of a task and engagement in it.

Based on the expectancy-value model of achievement motivation, learners' academic engagement is best predicted by the combination of students' expectancy, ability beliefs and task values both directly and indirectly (Wigfield \& Eccles, 2000), and research has provided support that ability beliefs are positively related to educational expectancy (Bandura, Barbaranelli, Caprara, \& Pastorelli, 2001; Trusty, 2000) and task values (Bong, 2001; Chouinard, Karsenti, \& Roy, 2007; Deci \& Ryan, 1985; Eccles \& Wigfield, 1995). Yet these beliefs and values vary from culture to culture and change in the process of learners' socialization in a certain culture (Eccles et al, $2004 \& 2008$ ).

\subsection{Gender Differences and Learner Motivation in EFL Context}

In the context of EFL learning, researchers have found some evidence implying the existence of gender differences in learner motivation and attitudes towards a target language. Most of the research done on the impact of gender differences on learner motivation indicate that females are more motivated and hold more favorable attitudes towards EFL learning than males (Ryan, 2009; William et al., 2002; Jones and Jones, 2001; Wong 2010; Kissau, 2006a; Henizmann, 2009; Fontecha, 2010). The findings of these studies are also supported by some studies in the context of Islamic world (Semmar, 2006; Schmidt et al., 1996). Despite the fact that there seems to be an agreement on the females' higher motivation for learning English as a foreign language, research has reported several contradictory voices as well (Suleiman, 1993; Jumani \& Basit, 2010; Spellerberg, 2011). These contradictory study results confirmed the notion of Eccles el at. (2004) in that gender influences on individuals' beliefs and values need to be further researched because within-cultural variation may produce greater differences than cross-cultural variation in some cases, especially in non-Western cultures with a salient linguistic and cultural identification.

Recent studies on the impact of gender differences in EFL learner motivation attribute gender differences to the globalization and ever-increasing impact of cultural influence on girls. Girls are found to be more interested in cultures and the people of the target language community than boys in most of EFL learning context (Dörnyei, 1998; Kang, 2000; Kang, 2000; Mori \& Gobel, 2006), yet there are some inconsistencies in these study results as well. For example: Mori \& Gobel (2006) and Shaaban \& Ghaith (2000) conducted studies to explore the gender differences in the EFL context by mixing the socio-educational and socio-psychological models of achievement motivation. In Mori and Gobel's study, Japanese female students were found to have greater integrativeness that concerns with students' attitudes towards the target culture and the future utility value of English in that culture, and no gender differences were found in students' attainment and intrinsic values and cost. Yet Shaaban and Ghaith found girls attached higher attainment value to English that led them make greater efforts than boys in Lebanon context. This inconsistency in empirical studies further enhances the importance of context in learner motivation.

Although there have been large bodies of research about the impact of gender differences on learner motivation in EFL context, most of them follow either the Gardnerian concepts of instrumentality and integrativeness or the mixture of socio-education and socio-phychological motivational theories. What is more, they showed different results and none of them used expectancy-value model alone that best suits the context where learners have less 
chance of traveling abroad and females are expected not to travel to distance regions alone. In such a context, gender differences will be more salient because of the parental and social expectations of males and females, the religious influence on education, traditional parents' anticipation of old-age support from their sons more than from their daughters, and economic reasons. Thus the following hypotheses and one research question are tested in the present study.

\section{H1: Female students will be more motivated than male students.}

\section{H2: Female students' EFL performance will be better than male students' EFL performance.}

If the above two hypotheses are supported, we will uncover the motivational factors that better predict the EFL learners' performance. Thus, the following research question evolves from the basis of the above hypotheses.

$R Q$ : What motivational factors are the best predictors of minority students' performance in the context of English as an L3 learned in L2?

\section{Social Background}

The Xinjiang Uyghur Autonomous Region is located in northwestern China, with a total area of 1.664 .900 square kilometers, which makes up one sixth of China's total territory. It is the largest provincial-level administrative region in the country. To the north, east, and west, Xinjiang shares its 5.600 kilometers of borders with eight countries: Russia, Mongolia, Kazakhstan, Kyrgyzstan, Tajikistan, Pakistan, India and Afghanistan. The region's location makes it a crucial part of the historical "Silk Road," as the strategic channel by which Eastern Asia connects to Central Asia, the Middle East, and Europe. Therefore, the Autonomous Region occupies a vital strategic position of international importance.

There are 13 ethnic minorities in Xinjiang with the total population of over 21 million according to the census in the year of 2010. Ethnic minorities account for $60.4 \%$ and nearly ten million Uyghurs make up some $45.9 \%$ of the total population of Xinjiang and $0.79 \%$ of the total population of China; nine million Han Chinese make up $41 \%$ of the total population of Xinjiang and $91.9 \%$ of the total population of China. Kazaks make up 7\%; and other nine ethnic minorities take $7.1 \%$.

With the development of globalization and increasing power of English as a global language, English education for the ethnic minorities in Xinjiang has become a serous research concern in the past few years. The status of English from selective course to compulsory one in the school curricula in universities and uprising of language training centers has proved the increasing role of English in minority education. During the 1990s, the minority students in this region formally learned English as a selective course only two hours per week and there were very few language-training centers available for them. With the guidelines of MoE (2001a,b and 2007), universities in Xinjiang have formally started teaching English as a compulsory course to minority students. Though English education of minority students in Xinjiang has already drawn the attention of researchers and scholars in and out side of China, nearly all of them focused on the external factors such as minority learners' unfavorable economic situation, lack of qualified English teachers from the ethnic groups who are bilingual in both Chinese and native language, lack of suitable teaching materials, trilingual program design, school circular, empirical research, poor performance in L2 and low motivation in learning L3, and the threats that two powerful languages (English and Chinese) bring to minority student home language and so on (Becket, 2012; Feng, 2009 \& 2011; Sunuodula and Feng, 2011; Jiang et. al.; 2007; Yang, 2005).

Although there are some studies on the English education of minority students in Xinjiang, none of them talks about the minority students' gender differences in L3 motivation. Studies (Glandy, 1999; Mackerras, 2003; Xu \& Jaschok, 2009) showed that religion has a strong influence on minority students' education in Xinjiang, because many parents prefer their children, especially daughters, to receive education in their native language and learn the basic knowledge of Qur'an so that they can transmit their cultural value to the next generation. This choice of schooling not only the outcome of parents' religious conservatism, but also derived from their anxiety to preserve their ethnic and cultural identity (Jaschok \& Chan, 2009). Although the above studies didn't mainly focus on minority students' gender differences in L3 motivation, the results gave some implications that parental expectation, religion and demographic change of the region has an impact on gender gap in the minority students' education, especially in the era of globalization and rapid economic development of China. Expectancy-value theory also emphasizes the importance of gender role in the cultural milieu component of learner motivation. If we based on this theory, I think the case of minority students in Xinjiang is worth researching, because they are not only influenced by religion, but also influenced by non-religious ideology of Chinese government in education. The issues and challenges underlying minority girls' education in Xinjiang interlink with complex religious, cultural and gender concerns at various levels of society. Thus, this study aims 
at finding answers to the above-mentioned two hypothesis and one research question from the individual's point of view, so that significant others such as teachers and policy makers will be able to better understand their students' needs and help them to perform well in L3.

\section{Methodology}

\subsection{Quantitative}

\subsubsection{Research Instrument and Its Administration}

The research instrument in this study is composed of two parts: a personal information sheet and a questionnaire on learner motivation (see appendix). The questionnaire about learner motivation is based the Motivational Scale by Wigfield \& Eccles $(1994 ; 2000)$, later modified by Ohki (2007) with a Likert-scale from strongly disagree to strongly agree. Some items in the questionnaire were modified according to the local context, and four items were added after its validity and reliability were confirmed.

\subsubsection{Participants and Medium of Instruction}

The participants were students, mainly Uyghur, from one of the top universities in the Xinjiang Uyghur Autonomous Region. The total number of participants in this study was 219 ( 75 male students and 144 female students-there were more female students than male students on whole in the university). The students majored in science and art: all of them reached the intermediate level in L2 proficiency required by school administration.

The present educational system for the minorities is Chinese-mother tongue (mainly Uyghur) bilingual education and its mode differs from region to region for various reasons. Regardless of the minority students' L2 level, they learn English as an L3 through L2 after they learn one-year preparatory Chinese as a better transition from L1 to $\mathrm{L} 2$ at college.

\subsection{Qualitative}

\subsubsection{Interviews}

To extract the reasons of minority students' learning English specifically, 30 students were interviewed for a more in-depth exploration into what the questionnaire responses might mean. Of whom, 11 were male students. For limited space, responses from 16 students are given here. $M$ stands for male and $F$ stands for female students.

Student 1 (F): Learning English is not only important in our university life, but also it has great impact on our future.

Student 2 (F): I am interested in English from my childhood. I am very pleased that we have the chance of learning it now.

Student 3 (F): English is very difficult, but I have to keep trying.

Student 4 (F): If we have a chance to go abroad in the future, English will surely plays an important role.

Student 5 (M): We have to make great effort if we want to learn English well.

Student 6 (M): I am interested in English and I will try hard to make progress in further study.

Student 7 (F): English is a global language and as a university student, we have to learn it.

Student 8 (M): English is very difficult, especially learning English in limited L2 proficiency, but I love it.

Student 9 (M): Whether we use English or not, it is worth learning

Student 10 (F): We have to take a serious attitude towards English. Even if I meet difficulties in learning English, I keep trying hard.

Student $11(\mathrm{M})$ : It is very difficult to memorize the English words. School should arrange more effective activities to learn English.

Student 12 (F): I love learning English. It is interesting and enriches our life.

Student 13 (F): We have only one or two year's English course, I want to learn more.

Student 14 (M): Sometimes I feel learning English is boring. But when I think carefully, it is useful in our life.

Student 15 (M): Don't want to learn at all.

Student 16 (F): English is important. If we have time, we must to learn English to enrich our life 
Form the extract above, it can be inferred that both male and female students are interested in English, and perceive it important and useful. These results are similar with the responses illustrated in the questionnaire. But in comparison to female students, male students think English more difficult and boring. One of them stated that learning English in limited L2 proficiency is difficult. This means that limited L2 proficiency that exacerbates the negative perception of difficulties of learning L3 might decrease male students' less interest than female students. One male student said: "It is very difficult to memorize the English words. Schools should arrange more effective activities to learn English" From this extract, it is easy to see that male students use less learning strategies and depend more on significant others such as school, teachers and peers to support them in L3 learning in comparison to female students. These results further confirm the study results that female students use more learning strategies than male students that lead to higher motivation and better performance (Chavez, 2001; Young \& Oxford, 1997).

On the contrary, most of the female students were optimistic about learning English. They claimed they are interested in learning English and would try hard even if it is difficult. Two of the female students said: "English is very difficult, but I have to keep trying. Even if I meet difficulties in learning English, I keep trying hard". From these statements, it is easy to indicate that female students make greater effort than male students. This result further supports the study results' of Shaaban \& Gaith (2000) in which female students placed more importance and make greater effort that leads to high interest and better performance. Two of the girl interviewees said that English enriched their life and had impact on their future. This means learning English is a good chance for them to empower themselves. With English knowledge, not only can they compete with their counter parts both inter-group and intra-group, and majority Han females at the job market but also they would like to be considered as able persons who can cope with the challenges come from locally, nationally and globally. This indicates that the knowledge of English will bring them a sense of safety, success and empowerment.

\section{Results and Discussion}

\subsection{Mean and Standard Deviation of Motivational Variables}

Table 1. Mean and standard deviation of each motivational variable

\begin{tabular}{llc}
\hline Variables & Mean & Standard Division \\
\hline Expectancy & 4.75 & .91 \\
Intrinsic value & 4.95 & .94 \\
Attainment value & 4.99 & .77 \\
Utility value & 5.12 & .71 \\
Cost & 4.04 & .56 \\
\hline
\end{tabular}

As shown in table 1, expectancy has a mean of (4.75), which ranked fourth among the motivational variables. It means that minority students' expectancy in learning L3 in L2 reaches "4" in the Likert-scale referred to the somewhat agree (e.g.: I am mastering what I have learnt in English. I am more competent in English than my classmates.). This is the fact that they are not fully confident in learning English in limited L2 proficiency. Though the minority students are not very confident in learning L3, they think it important. This might be the increasing status of English given in China and its ever-enhancing power in the world. The intrinsic and attainment value have means of (4.95) and (4.99) respectively, near to " 5 " in the Likert-scale referred to agree (it is a pleasure to learn English. I think it important to learn English besides Chinese.). These figures indicate that minority students attribute an important role to English in their future besides Chinese.

Utility value has the highest mean among the five motivational variables (5.12), between " $5 \sim 6$ " in the Likert-scale referred to agree and strongly agree (Learning English is useful to find a good job after my graduation. Learning English is useful to go abroad later). This figure further confirms the instrumentality of EFL learner motivation found in the past research results in China (Gao, 2004; Hu \& Alsogoff, 2010; Pan \& Block, 2011). They are fully aware that they cannot survive in the globalized era with Chinese only, especially in the job market where they compete with Han majority students who learn English as a compulsory course from elementary grade three. Moreover, the increasing number of international students from border countries would be one more reason to enhance the utility value of English. 
Lastly, cost has the lowest mean of (4.04) and standard deviation of (.56.) Their responses are neutral as " 4 " in the Likert-scale referred to the somewhat agree (e.g.: Learning English in Chinese is very difficult for me. I have to give up my own interest to study English). This indicates that although they reach the required level in L2 proficiency when English course formally began to be taught, it is not certain that they fully understand the content of the course. They feel English somewhat difficult even though they are beginners. This result further supports the idea of Ushioda (2006) that minority students' EFL motivation in Xinjiang is never simply in the hands of minority students themselves, but it is constructed and constrains through the present Chinese-mother tongue bilingual language policy. Since all scales have a mean value above 4 , it can be said that minority students in Xinjiang hold positive motivational disposition towards learning English.

\subsection{Correlations of Each Motivational Variable}

Table 2. Correlation analysis of each motivational variable

\begin{tabular}{lllllll}
\hline & Expectancy & Intrinsic & Attainment & Utility & Cost & Test \\
\hline Expectancy & - & $.365^{* *}$ & $.329^{* *}$ & $.241^{* *}$ & -.090 & $.303^{* *}$ \\
Intrinsic & & - & $.497^{* *}$ & $.377^{* *}$ & $-.277^{* *}$ & $.235^{* *}$ \\
Attainment & & & - & $.493^{* *}$ & $-210^{* *}$ & $.238^{* *}$ \\
Utility & & & - & - & $-.165^{*}$ & .079 \\
Cost & & & & - & - & $-.358^{* *}$ \\
\hline$* * \mathrm{p}<.01 ; * \mathrm{p}<.05$ & & & & & &
\end{tabular}

As shown in table 2, correlation analysis was performed to confirm the associations of each motivational variable. Concerning correlation of each motivational variable, the strongest statistical significant positive correlation appears between intrinsic and attainment value $(\mathrm{r}=.50)$. They also strongest significant negative correlates with cost $(\mathrm{r}=.-.28 ; \mathrm{r}=-.21)$ respectively.

Regarding the correlations of motivational variables with test scores, it strongly and negatively significantly correlates with cost $(\mathrm{r}=.-36)$ and positively correlates with expectancy $(\mathrm{r}=.30$;). This suggests that in such a context where a test score is highly valued, learner expectancy and cost are the strongest motivational factors to predict learner performance in comparison to other motivational variables.

\subsection{Gender}

Table 3. T-test results

\begin{tabular}{llllll}
\hline Gender & Male & \multicolumn{4}{c}{ Female } \\
\hline \multirow{2}{*}{ expectancy } & Mean & SD & Mean & SD & t-value \\
intrinsic & 4.678 & 1.250 & 4.779 & .681 & -.652 \\
attainment & 4.779 & .7942 & 5.094 & .580 & $-.3 .043^{* *}$ \\
utility & 5.031 & .798 & 5.174 & .662 & -1.407 \\
cost & 4.138 & .587 & 3.989 & .548 & 1.853 \\
test & 76.250 & 13.901 & & & $-3.274^{* *}$ \\
& & & 82.199 & 11.792 & \\
\hline
\end{tabular}

${ }^{* *} \mathrm{p}<.01 ; * \mathrm{p}<.05$

As shown in table 3, means of all motivational variables except for cost in female students were higher in comparison to male students and vice-versa. T-test results showed that intrinsic and attainment values of female students were significantly higher than male students' $\left(\mathrm{t}=-3.32^{* *} ; \mathrm{t}=-.3 .04 * *\right)$. These results further confirmed the previous study results that female students were more interested in interaction with the target culture (Hyde, 1996) and placed more importance than male students (Shaaban, 2000). There were also high statistical 
significant differences between the test performances of males and females $\left(\mathrm{t}=-.3 .28^{* *}\right)$. This findings also confirmed the past study results that the more interest and personal importance learners placed on a given task, the better self-determined and self-regulated they were. The better self-determined and self-regulated they were, the higher their performances were (Gardner, 2002; Reza, 2012; Crooks \& Schmidt, 1991; Mounawar, 2003; Eccles al et., 2004).

4.4 Results of Multiple Regression Analysis

Table 4. Regression analysis of motivational variables with test scores for whole

\begin{tabular}{|c|c|c|c|c|c|}
\hline & \multicolumn{2}{|c|}{ Unstandardized Coefficients } & \multicolumn{2}{|c|}{ Standardized Coefficient } & \\
\hline & B & Std. Error & Beta & $\mathrm{T}$ & Sig. \\
\hline constant & 87.95 & 10.31 & & 8.53 & .000 \\
\hline expectancy & 3.46 & .992 & .237 & 3.49 & .001 \\
\hline intrinsic & .514 & 1.02 & .038 & .505 & .614 \\
\hline attainment & 2.54 & 1.45 & .035 & 1.75 & .081 \\
\hline utility & -2.16 & 1.31 & -.119 & -1.65 & .101 \\
\hline cost & -7.06 & 1.48 & -.305 & -4.77 & .000 \\
\hline
\end{tabular}

Table 5. Regression analysis of motivational variables with test scores for females

\begin{tabular}{lccccc}
\hline & \multicolumn{2}{l}{ Unstandardized Coefficients } & \multicolumn{2}{l}{ Standardized Coefficient } & \\
\hline & $\mathrm{B}$ & Std. Error & Beta & $\mathrm{T}$ & Sig. \\
constant & 89.8 & 13.24 & & 6.75 & .000 \\
expectancy & 5.04 & 1.79 & .254 & 2.82 & .006 \\
intrinsic & -.462 & 1.33 & -.030 & -.348 & .728 \\
attainment & 2.48 & 1.82 & .123 & 1.36 & .175 \\
utility & -2.21 & 1.49 & -.124 & -.1 .48 & .141 \\
cost & -7.59 & 1.68 & -.352 & -4.52 & .000 \\
\hline
\end{tabular}

Table 6. Regression analysis of motivational variables with test scores for males

\begin{tabular}{lccccc}
\hline & \multicolumn{2}{c}{ Unstandardized Coefficients } & \multicolumn{2}{c}{ Standardized Coefficient } & \\
\hline \multirow{2}{*}{ constant } & $\mathrm{B}$ & Std. Error & Beta & $\mathrm{T}$ & Sig. \\
expectancy & 91.03 & 17.93 & & 5.08 & .000 \\
intrinsic & .816 & 1.32 & .270 & 2.23 & .029 \\
attainment & .550 & 1.76 & .069 & .463 & .645 \\
utility & -1.872 & 2.61 & .032 & .211 & .834 \\
cost & -6.144 & 2.55 & -.107 & -.733 & .466 \\
\hline
\end{tabular}

As shown in table 4, 5, and 6, multiple regression analyses were conducted to identify the motivational factors that predict the minority students' EFL performance and the results showed that expectancy and cost have statistical significant effect on minority students' EFL performance. Of these two variables, cost seems to be a stronger predictor than expectancy (-.31). This is not surprising in the case of Xinjiang where minority students learn L3 in limited L2 proficiency that causes the cost of learning English moderately high. Although there was no statistical significant effect of intrinsic and attainment value on test scores revealed, as can be seen from the illustrated significant correlations, cost had the strongest negative correlation with intrinsic and attainment value. These results further confirm the previous study results that when the task is too difficult to understand, learners 
will easily be lost, feel less confidence or bored (Eccles and Wigfield, 2002; 2010; Dörnyei, 1998).

The second motivational variable that predicted the minority students' EFL performance is expectancy. It is interesting that there were no statistical significant correlations reveal between cost and expectancy illustrated in Table 2. This seems to be the affect of evaluation system of students' English performance and the content of exam. In the case of English exam, students try their best to pass the exam by employing different methods such as rote learning, cheating or asking help from significant others, because of the evaluation system in which exam results are the stakeholder of everything from receiving grants to getting graduate certificates. These results are not surprising and further support the previous study results of Han majority EFL learners' certificate motivation (Tang, 2005; Pan \& Block, 2011) in China. In other words, EFL learners in China are motivated to get certificates that help them climb up the social ladder.

\section{Conclusions, Educational Implications and Limitations}

On the base of expectancy-value theory of achievement motivation, this study aimed to explore the effects of gender differences on learner motivation and the motivational variables that better predict the learner performance in the context of English as an L3. The two hypotheses were confirmed that female students hold greater intrinsic and attainment value than male students, and therefore their performance is better than male students.

Regarding the gender differences, this study results are explained by the changing value beliefs of minority peoples, namely Uyghurs in the region from the following points of view. First, in the old Uyghur society, there was a firm belief among Uyghurs that it was men's responsibility to support the family, and it was believed that a husband should protect his wife and children from anything harmful. This belief brought a sense of safety for women, and males were really able to do that by working hard outside. Now this is not the case. The increasing cost of living and unemployment among the minorities made it difficult for males to support their family alone. Thus, in rural areas, many parents prefer their sons to learn various skills after the compulsory education is over to sending them to college; instead they invest in education for their daughters more. As girls are neither allowed to go to the Islamic schools nor to follow the Islamic rules such as wearing Islamic dresses at secular schools, many parents in the rural areas want their daughters to receive better education to keep and transmit their cultural values. These results further confirm the post study results by Jaschok \& Chan (2009). Second, with the economic development and the change of geopolitical situation of this region, women's social status and mobility has increased, yet they are confronting more challenges than ever before. Third, the negative beliefs of task difficulty most probably hinders the male students' intrinsic and attainment value in L3. The results of this study further confirm the worries of scholars (Feng, 2009; Sanaydulla; 2011; Zhang, 2005) that minority students are at disadvantage position in L3 learning not only economically, but also linguistically. Thus further study on the impact of gender differences on minority students' L2 motivation will help to better understand their motivational differences in L3 learning.

Regarding the motivational variables that better predict the minority students' EFL performance, students' expectancy and cost are considered as main causes. As mentioned before, learning L3 in limited L2 proficiency increases the cost of learning English high, which in turn, negatively affect other motivational variables. Judging from the correlation analysis, if the learners' intrinsic and attainment value increases, their expectancy in learning L3 increases and cost decreases as well.

As an educational implication of this study, the medium of $\mathrm{L} 3$ instruction needs to be taken into consideration. It is important for teachers to keep in mind the L2 proficiency of the minority students that has direct impact on their cost of L3 learning. Thus teachers try to avoid exclusive use of L2 although this is not the issue that teachers decide. In order to motivate their male students and increase their EFL performance, teachers need to be more supportive for male students and help them to set future goals. Students' sense of competence is enhanced when teachers provide support through instruction in strategies, skills, and satisfaction of relatedness needs enhances student interest, participation, and academic effort (Blumenfeld et.al., 2012; Wentzel, 1997). As researchers Csizér \& Dörnyei and Kormos \& Csizér (2005b; 2008) claimed, the importance of devoting time and resources at an early stage of FEL learning to enhance the FEL self-concepts of boys needs to be strongly emphasized.

As limitations, the questionnaire in this study focuses on the cognitive part of the ethnic minority learners' L3 motivation in Xinjiang, the external factors such as school system, the role of teachers and parents are equally important. So that we, teachers are able to motivate our students and educate trilingual talents who can act locally, nationally and internationally at the same time. There is a need to explore the gender differences in their motivation of other school subjects as well as the gender differences between different ethnicity, namely Han and 
Uyghur. The results of this study cannot be generalized to the other four autonomous regions in China, because of following reasons. Firstly, different modes of bilingual education applied to ethnic minority education in Xinjiang will lead to different L2 proficiency. Secondly, the exposure to L2 is largely different from region to region because of the population density of Han majority, and this might affect the minority students' L2 proficiency that contributes the increase of cost in learning L3. Thirdly, language and religion may also be at play. These factors may positively or negatively impact the minority students L3 motivation in Xinjiang where they learn L3 in limited L2 proficiency. Last but not least, the minority students' motivation towards two powerful languages: national language--Chinese and international language-English is equally important to be explored.

\section{References}

Adamson, B., \& A.W. Feng. (2009). A comparison of trilingual education policies for ethnic minorities in China. Compare, 3(3), 321-332. http://dx.doi.org/10.1080/03057920802436258

Bachford. D., \& Jones. M. (2011). Trilingual education policy ideals and realities for Naxi in rural Yunnan. In Feng. A (Eds.), English language education across greater China. Multilingual Matters, 228-259.

Bernat. E., \& Lloyd. R. (2007). Exploring the gender effect on EFL learners' beliefs about language learning. Australian Journal of Educational \& Developmental Psychology, 7, 79-91. Retrieved from http://www.newcastle.edu.au/group/ajedp/

Bernaus, M., \& Gardner, R. C. (2008). Teacher motivation strategies, student perceptions, student motivation, and English achievement. The Modern Language Journal, 92(3), 387-401.

Blumenfled, al et. (2012). Motivation and Cognitive Engagement in Learning Environments. The Cambridge handbook of learning Sciences (pp. 475-488). Cambridge University Press.

Csizér, K., \& Z. Dörnyei (2005b). The internal structure of language learning motivation and its relationship with language choice and effort. Modern Language Journal, 89, 19-36.

Deci, E. L., \& Ryan, R. M. (1985). Intrinsic motivation and self-determination in human behavior. New York: Plenum.

Eccles, S. (1994). Understanding women's educational and occupational choices. Psychology of Women Quarterly, 18(4), 585-609.

Gladney, D. C. (2004). Dislocating China. Muslims, minorities and other subaltern Subjects. Hurst \& Company, London.

Jaschok. M., \& Chan. H. (2009). Education, gender and Islam in China: The place of religious education in challenging and sustaining 'undisputed traditions' among Chinese Muslim women. International Journal of Educational Development, 29(5), 487-494. http://dx.doi.org/10.1016/j.ijedudev.2009.04.004

Kissao, S. (2006). Gender Differences in Motivation to Learn French. The Canadian Modern Language Review, 62(3), 401-422. http://www.utpjournals.com/cmlr/cmlr623.html

Mackerras, C. (2003). China's Ethnic Minorities and Globalization. Routledge Curzon, New York.

Macpherson. S., \& Beckett. G. (2008). The hidden curriculum of assimilation in modern Chinese Education: Fueling indigenous Tibetan and Uyghur cessation movement. In Z. Bekerman, \& E. Kopelowitz (Eds.), Cultural education, cultural sustainability: minority, diaspore, indigenous and ethno-religious groups in multicultural societies (pp. 103-122). Routledge New York.

MoE (2001，4 号)教育部关于加强高等学校本科教学工作 提高教学质量的若干见 (Guidelines on strengthening university undergraduate teaching and raising teaching standards). Retrieved from http://www.pgzx.edu.cn

MoE (2007, 2 号)教育部关于进一步深化本科教学改革全面提高教学质量的若干意见. (Guidelines on further deepening the educational reform of undergraduate teaching and strengthening the educational quality). Retrieved from http://www.chinalawedu.com

Spellerberg, S. (2011). L3 English acquisition in Denmark and Greenland: gender-related tendencies. International Journal of Multilingualism, 8(3), 155-188. http://dx.doi.org/10.1080/14790718.2011.578747

Sunuodula, M., \& Feng, A. (2011). Learning English as a third language by Uyghur students in Xinjiang. In Feng. A. (Eds.), English education across greater China (pp. 260-271). Multilingual Matters.

Wigfield, al et. (2004). Expectancy value theory in cross-cultural perspective. Research on Social Cultural Influences on Motivation and Learning, 4, 165-198. 
Wigfield, al et. (2000). Expectancy-value theory of achievement motivation. Contemporary Educational Psychology, 25, 68-81.

Wentzel, K. R. (1997). Student motivation in middle school: the role of perceived pedagogical caring. Journal of Education Psychology, 89(3), 411-419.

Xu, L. L., \& Jaschok, M. (2009). Qiayi. A preliminary study of Uyghur Xinjiang women. Minzu Yanjiu (Nationality Research). Chinese Academy of Social Sciences, Beijing.

Yang, J. (2005). English as a third language among China's ethnic minorities. International Journal of Bilingual Education and Bilingualism, 8(6), 552-567. http://dx.doi.org/10.1080/13670050508669068

\section{Appendix}

1. I am mastering what I have leant.

2. I am more competent in my English than my classmates.

3. I think I will get good grades in my next English test.

4. I think I can achieve my goal successfully in learning English.

5. I think I can master English.

6. It is important for me to have good grades in English.

7. I want to do well in my English study.

8. It is worth learning to master English.

9. It is important for me to be able to use English completely in all situations.

10. It is a pleasure to learn English.

11. I like learning English.

12. The acquisition of English is useful to my plans after leaving university.

13. What I have learnt in the English course will be useful for my future profession.

14. English is difficult for me.

15. To get good grades in English, I have to work hard.

16. To acquire master of English, I can give p other pleasures.

17. Learning English is a burden (painful) in several ways.

18. It is important to be someone who can see things from the prospective of English speakers.

19. Learning English in Chinese is very difficult for me.

20. Learning English is useful for me to go abroad

21. I think English plays an important role in developing Xinjiang.

\section{Copyrights}

Copyright for this article is retained by the author(s), with first publication rights granted to the journal.

This is an open-access article distributed under the terms and conditions of the Creative Commons Attribution license (http://creativecommons.org/licenses/by/3.0/). 